\title{
Shiga Toxin Beta Subunit
}

National Cancer Institute

\section{Source}

National Cancer Institute. Shiga Toxin Beta Subunit. NCI Thesaurus. Code C20073.

The non-catalytic beta subunit of Shiga toxin may be useful as a fusion vector for induction of antigen-specific cytotoxic T lymphocyte responses. 